\title{
A SIMPLE SELF-CLAMPED HIGH STEP-UP DC-DC CONVERTER EMPLOYING COUPLED INDUCTOR
}

\author{
Eduardo S. Hass; Claudinor B. Nascimento \\ Department of Electrical Engineering, Federal University of Technology of Parana (UTFPR), Ponta \\ Grossa- PR, Brazil \\ e-mail: eduardohass27@hotmail.com, claudinor@utfpr.edu.br
}

\begin{abstract}
This paper proposes a high-voltage-gain boost-based converter employing a coupled inductor. The proposed circuit presents high efficiency, absence of clamping circuits for limiting the voltage spikes over all semiconductor devices and reduced number of components. Besides employing a coupled inductor, the converter also has two stacked capacitors in its output. Thus, the total voltage gain is defined by the duty cycle, the turns ratio of the coupled inductor and the sum of these two capacitor voltages, resulting in the high gain of the system. It is demonstrated that the efficiency is high, because extreme duty cycle values are avoided. Its steadystate operating principle are presented. So, it can be observed that maximum voltage spikes on the all semiconductors (main switch and diodes) is equal to the output voltage Vo, turning the proposed converter suitable for applications where voltage levels on the load need to be not too high $(400 \mathrm{~V}-600 \mathrm{~V})$. Finally, experimental results in by open loop control are presented for $30 \mathrm{~V}$ and $48 \mathrm{~V}$ input voltages, $400 \mathrm{~V}$ output voltage, $100 \mathrm{kHz}$ switching frequency and $300 \mathrm{~W}$ output power.
\end{abstract}

Keywords - Boost converter self-clamped; High efficiency; Step-up dc-dc converter.

\section{INTRODUCTION}

Electricity, besides observed in nature as a physical phenomenon such as electrostatic discharge, is neither found nor produced so simply. To produce electricity and use it on his own advantage, mankind usually makes use of nonrenewable natural resources such as oil, coal and natural gas and renewable sources such as solar, biofuels and water. Given that natural fossil sources are limited and, as far as they are consumed, they cause irreparable harm to the environment and to many forms of life, other renewable sources are also being used more intensively to produce electric energy. According to the U.S. EIA (Energy Information Administration), energy production from alternative sources is expected to increase by an average of $2.3 \%$ per year by 2040 [1]. In this sense, it can be said that the generation of energy from renewable sources such as wind, solar and fuel cells is no longer an option but a necessary reality. However, controlling and conditioning the energy provided by these sources are performed by systems

Manuscript received 11/02/2019; first revision 02/04/2019; accepted for publication 23/05/2019, by recommendation of Editor Marcello Mezaroba. http://dx.doi.org/10.18618/REP.2019.2.0009 that have their own operating characteristics and are subject of study by many experts around the world. One of the main challenges is to get energy to reach its destination loads with minimum waste [2]. Therefore, the use of switching power converters for interconnecting the generation source and the

load is the best option to condition and control the flow of energy and achieve the desired efficiency levels [3]-[8].

Regarding the electronic processing of energy from fuel cells and photovoltaic systems, a dc-dc converter operating at high frequency is commonly used [3]-[31]. For achieving a high efficiency, some operating characteristics of the circuit are desirable, like reduced conduction and switching losses, low voltage clamping on the semiconductors, energy regeneration during the switching process without employing auxiliary circuits, supply continuous current from the input power source and low component count. Providing all these characteristics into a unique converter is not an easy task and is hardly achieved. Photovoltaic panels and fuel cells produce energy at very low voltage levels and, generally, it is necessary to process it in order to get far higher levels. In this sense, most proposals employ topologies based on coupled inductors [3]-[18]. It is known that classic step-up converters like the boost is not appropriate in most cases, because the voltage gain depends only on the duty-cycle [3]. In such case, due to non-idealities present in the circuit elements, the global efficiency becomes too low at high duty-cycle values [3]-[7]. On the other hand, due to the leakage inductance, in topologies that employs inductors with two or more coupled windings to rise the voltage gain, auxiliary circuits for clamping the semiconductors voltage spikes are necessary on most cases, which increases the number of components and may reduce efficiency [3]-[7], [11]. Other non-boost-based configurations are also used in order to raise the voltage gain. In such cases, the component count may become expressive, as in circuits that employs voltage multiplying cells [3]-[7], [16]-[17].

In most papers found in the literature, generally in order to obtain high-voltage gain and to avoid voltage spikes on the switches, clamping circuits (passive or active) and power devices such as diodes and capacitors has been added to the switched-mode converters [6],[10],[16],[20]-[21]. The increase of power devices and passive components count, as well as of clamp circuits, can reduce the overall system efficiency. However, in applications where the output voltage levels need not be too high, due to advances of semiconductor technologies which have low drain-source on-state resistance such as CoolMOS ${ }^{\mathrm{TM}}$ Silicon (Si), Silicon Carbide ( $\mathrm{SiC}$ ) and Gallium Nitride (GaN) [30], it is possible to employ simple topologies without adding many components such as in the proposed converter. In this work, 
a high gain and high efficiency boost-based dc-dc converter with coupled inductor is proposed. This circuit presents natural voltage clamping on all semiconductor devices (MOSFET and diodes) without needing auxiliary circuits, thus contributing to reducing the total number of components. Furthermore, due to a low blocking voltage level on the main switch during the turn-on transition period, the switching losses are low, helping to increase the overall system efficiency. However, the maximum voltage spikes on all semiconductors are equal to the output voltage and the input source supplies a pulsating current which needs an input filter in some applications. In this case, the component count can be similar to the topologies that performance naturally continuous input current.

Experimental results are presented for an input voltage between $30 \mathrm{~V}$ and $48 \mathrm{~V}, 400 \mathrm{~V}$ output voltage, $100 \mathrm{kHz}$ switching frequency and $300 \mathrm{~W}$ output power.

\section{PROPOSED TOPOLOGY}

The proposed topology studied in this work is presented in Figure 1.a. It can be noted that the input stage comprises the coupled inductor primary-side winding, with its magnetizing inductance $L_{m}$, and the switch $S$. The inductance $L_{k}$ represents the leakage inductance of the coupled inductor. The output stage consists of the coupled inductor secondaryside winding, two diodes $D_{1}$ and $D_{2}$, and two capacitors $C_{l}$ and $C_{2}$. By details analysis, some important operational characteristics can be observed, like the definition of $V_{o}$ as the sum of voltages $V_{C l}$ and $V_{C 2}$ and that it can be observed that maximum voltage spikes on the all semiconductors (main switch and diodes) is equal to the output voltage $V_{o}$. Due to $D_{2}$ connection, the system becomes non-isolated. During the initial period of the converter operation after reaching the steady state, the coupled inductor performs like a conventional transformer, because both primary and secondary windings process energy during the whole interval

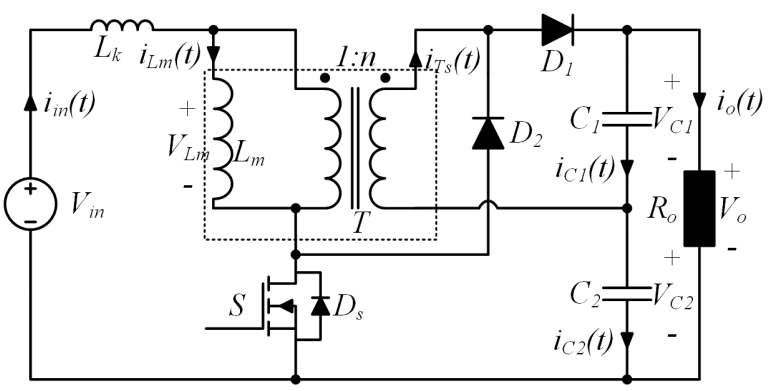

(a)

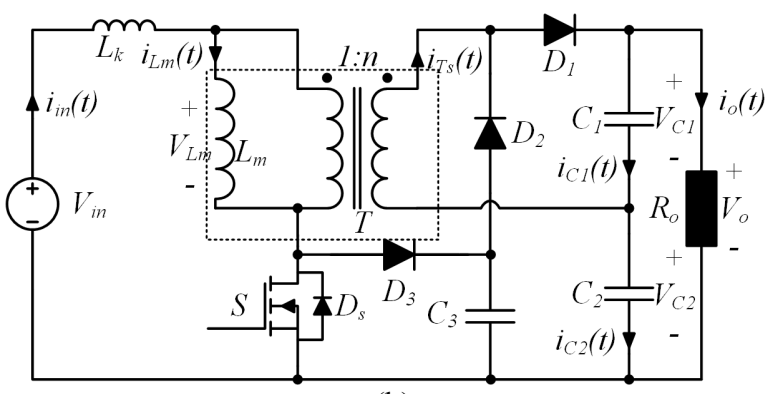

(b)

Fig. 1. Proposed topology: (a) Proposed self-clamped high stepup dc-dc converter; (b) alternative proposed high step-up dc-dc converter.
$T_{s}$. Then, despite being very similar to the boost-flyback configuration presented by [7], its operation principle, and consequently its mathematical model, are different, thus requiring an exclusive design methodology.

An alternative for reducing the maximum blocking voltage $\left(V_{D S \max }=V_{o}\right)$ on the switch $S$ in the circuit shown in Figure 1.a, is by including the capacitor $C_{3}$ and the diode $D_{3}$, as shown in the Figure 1.b. In this case, compared to the circuit of Figure 1.a, both conduction and switching losses should be lower because $R_{D S o n}$ of $S$ is reduced as well as the blocking voltages on all semiconductor devices. However, even though it is an interesting topology which also performs high-step up voltage and high-efficiency, its structure does not satisfy the main scope of this work which it is the use of a circuit made with reduced component counts for applications that requiring output voltage at levels between 400 and 600 volts. Thus, it is possible to employ semiconductor technology previously introduced in the work.

\section{A. Operation Principle in Steady-State}

After a detailed analysis of the converter in steady-state, considering the influence of the leakage inductance $L_{k}$ in the circuit, four operation stages can be verified over a cycle of the switching frequency $f_{s}$. During the stages, the following conditions are considered:

1) The voltages across capacitors $C_{1}$ and $C_{2}$ are assumed constant and ripple-free;

All the semiconductor elements are assumed as ideal;

2) $L_{k}$ corresponds to the total leakage inductance of the primary and secondary windings.

In the development of the mathematical model that represents the converter behavior in steady state, the following expressions are considered:

$$
\begin{aligned}
& \Delta t_{i}=t_{i}-t_{i-1} ; \quad v_{L}(t)=L \frac{d i_{L}(t)}{d t} ; \quad T_{s}=\frac{1}{f_{s}} ; \\
& \lambda=\frac{L_{k}}{L_{m}} ; \quad M=\frac{V_{o}}{V_{i n}} ; M_{C 1}=\frac{V_{C 1}}{V_{i n}} ; M_{C 2}=\frac{V_{C 2}}{V_{\text {in }}} .
\end{aligned}
$$

Where $i$ is the index that defines the time interval of each stage, which starts at $t_{i-1}$ and ends at $t_{i}$.

First operation stage $\left(t_{0}, t_{1}\right)$ : Previous to this stage, switch $S$ and diode $D_{1}$ were off, while $D_{2}$ was on, thus conditioning $C_{2}$ to receive part of energy from the leakage inductance $L_{k}$ and magnetizing inductance $L_{m}$, while $C_{l}$ along with $L_{k}$ and $L_{m}$ were providing energy to the load. At $t_{0}, S$ is turned on. From this moment on, the current of $L_{k}\left(i_{i n}\right)$ begins to raise linearly, while $D_{2}$ is still conducting and $D_{1}$ is still blocked. During this interval, $C_{2}$ receives energy from input supply $V_{\text {in }}$ and from $L_{m}$ and $C_{l}$ supply the load. In this stage, the voltage across $L_{m}$ is equal to $-V_{C 2} / n$, where $n$ is the turns-ratio of primary to secondary windings. This stage ends when the current in $L_{k}$ equals the current in $L_{m}$, and the current in diode $D_{2}$ becomes null, and it blocks. Figure 2.a shows this operation stage and equations (2) and (3) the behavior of currents in $L_{k}$ and $L_{m}$, according to Figure 3.

$$
I_{k 1}=I_{k 0}+\left(1+\frac{M_{C 2}}{n}\right) \cdot \frac{V_{i n} \cdot \Delta t_{1}}{\lambda L_{m}},
$$




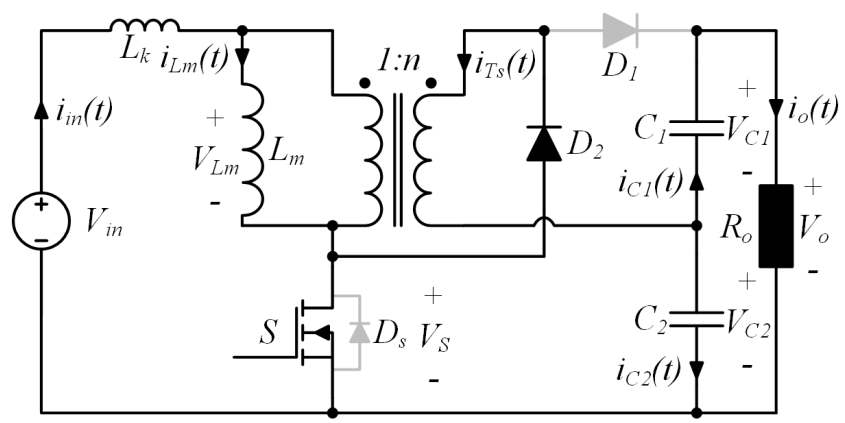

(a) First stage

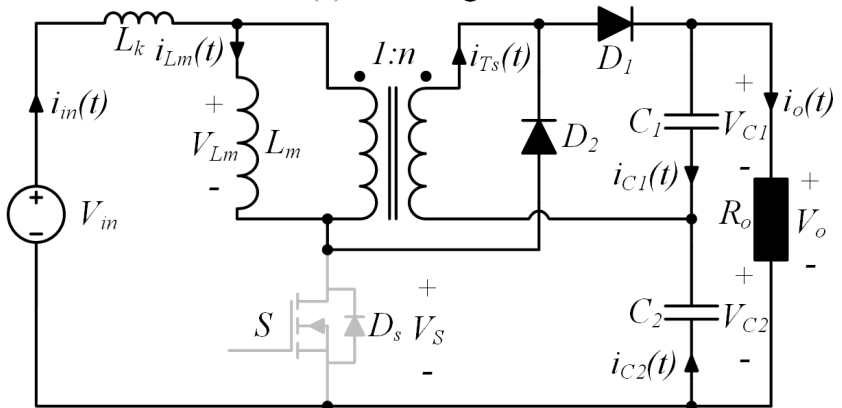

(c) Third stage

Fig. 2. Operation stages.

$$
I_{m 1}=I_{m 0}-\frac{M_{C 2}}{n} \cdot \frac{V_{i n} \cdot \Delta t_{1}}{L_{m}} .
$$

Second operation stage ( $\left.t_{1}, t_{2}\right)$ : At $t_{1}, D_{2}$ blocks and $D_{l}$ starts conduction. From this moment on, $L_{m}$ and $C_{1}$ receive energy from the input voltage $V_{i n}$, and $C_{2}$ provides energy to the load. The voltage across $L_{m}$ is $V_{C l} / n$. In this interval, considering the resistance of $S\left(R_{S o n}\right)$ equal to zero, the leakage inductance $L_{k}$ stores energy provided by $V_{i n}$ and its current increases linearly. Under real operating conditions, the voltage $V_{\text {Son }}$ across $S$ might be large enough and the $L_{k}$ current might decrease rather than increase. This stage ends when $S$ is turned off and $D_{2}$ starts conduction again along with $D_{l}$. Figure $2 . \mathrm{b}$ shows this operation stage and equations (4) and (5) the behavior of currents in $L_{k}$ and $L_{m}$, according to Figure 3.

Third operation stage (t, $\left.t_{3}\right)$ : At $t_{2}, S$ turns off and $D_{2}$ starts conduction along with $D_{l}$, thus ensuring voltage clamping on switch $S$ equal to the output voltage $V_{o}$. In this stage, the energy stored in $L_{k}$ is sent to the capacitors $C_{1}, C_{2}$ and to the load witch also receives energy from $V_{i n}$. During this stage, the voltage across the inductor $L_{m}$ is still $-V_{C I} / n$. This stage ends when the current of $L_{k}$ reaches zero, and $D_{2}$ blocks. Figure 2.c presents this operation stage and equations (6) and (7) the behavior of currents in $L_{k}$ and $L_{m}$, according to Figure 3.

$$
\begin{gathered}
I_{k 2}=I_{k 1}+\left(1-\frac{M_{C 1}}{n}\right) \cdot \frac{V_{i n} \cdot \Delta t_{2}}{\lambda L_{m}}, \\
I_{m 2}=I_{m 1}+\frac{M_{C 1}}{n} \cdot \frac{V_{i n} \cdot \Delta t_{2}}{L_{m}} . \\
I_{k 3}=I_{k 2}+\left(1-M-\frac{M_{C 1}}{n}\right) \cdot \frac{V_{i n} \cdot \Delta t_{3}}{\lambda L_{m}}, \\
I_{m 3}=I_{m 2}+\frac{M_{C 1}}{n} \cdot \frac{V_{i n} \cdot \Delta t_{3}}{L_{m}} .
\end{gathered}
$$

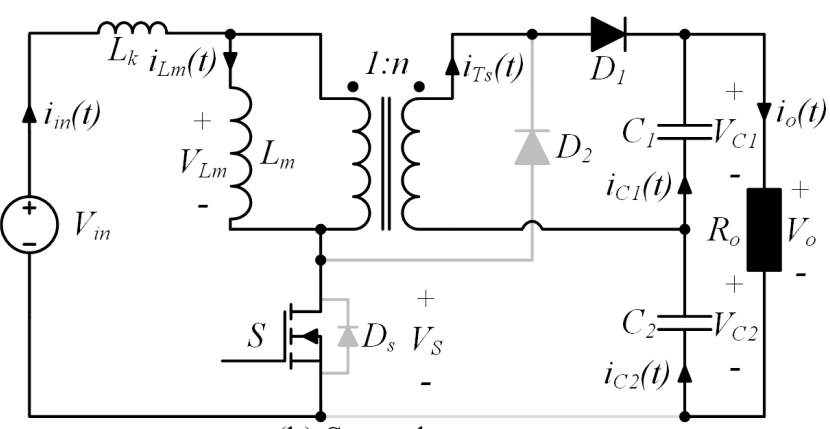

(b) Second stage

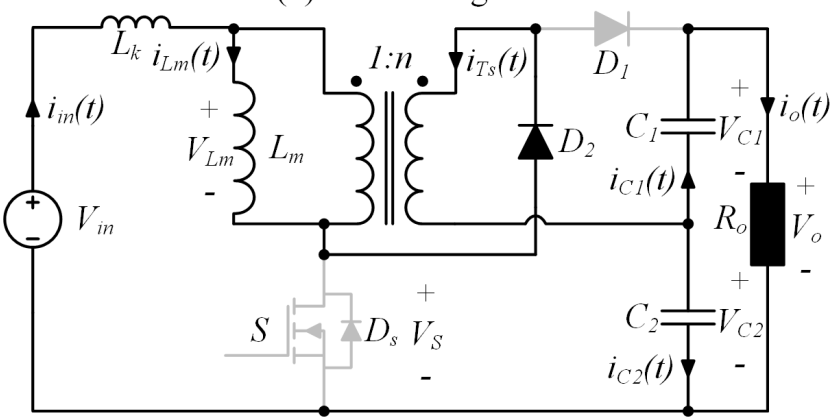

(d) Fourth stage

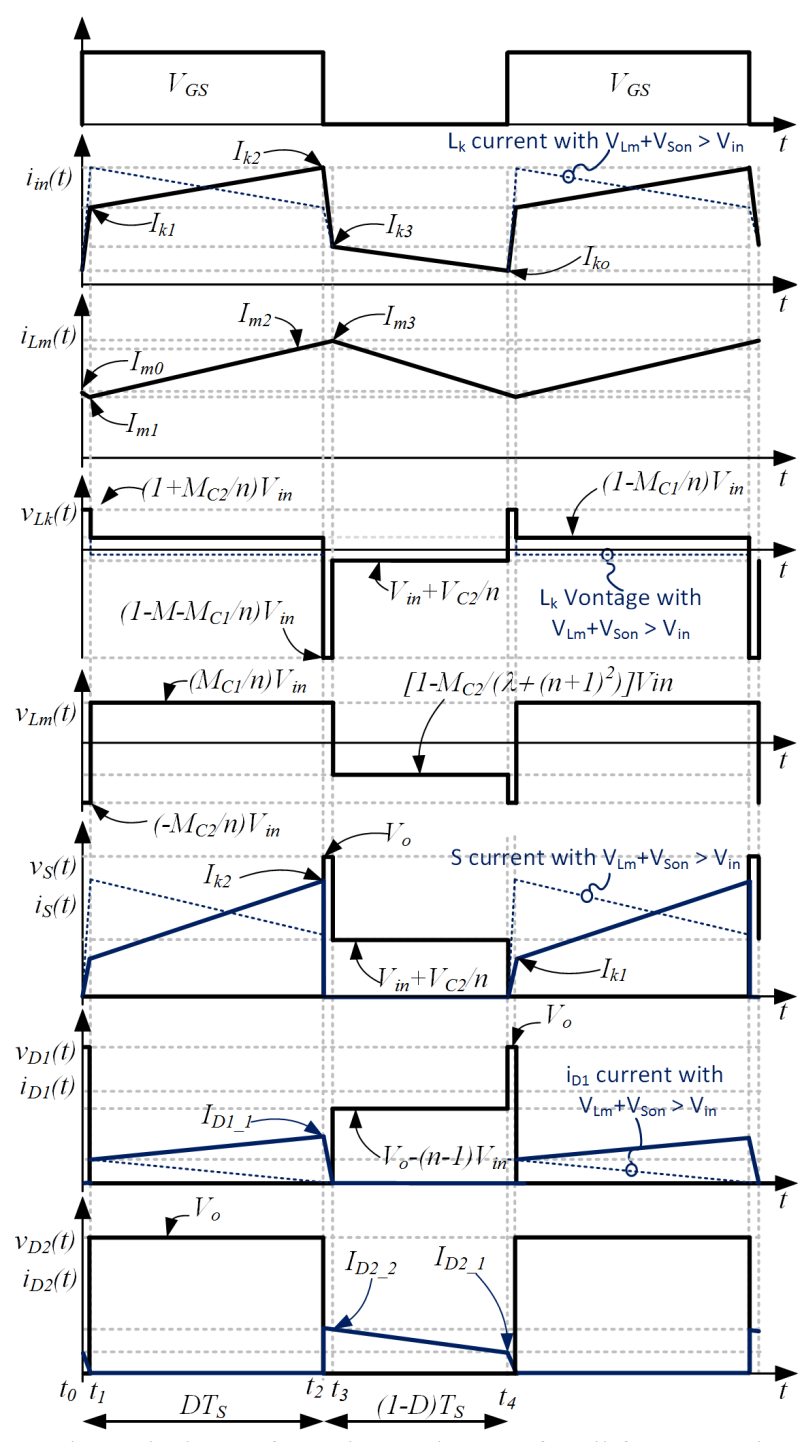

Fig. 3. Theoretical waveforms in steady-state for all four operation stages. 
Fourth operation stage (t3,t $\left.t_{4}\right)$ : At $t_{3}, D_{1}$ blocks and $D_{2}$ keeps conducting. The load then receives energy from $C_{l}$, while $C_{2}$ from $L_{m}$. In this stage, the voltage across $L_{m}$ becomes $-V_{C 2} / n$ and the current in $L_{k}$ is still rising. This stage ends when $S$ is turned on and the first stage starts again. Figure 2.d presents this operation stage and equations (8) and (9) the behavior of the currents in $L_{k}$ and $L_{m}$, according to Figure 3.

$$
\begin{gathered}
I_{k 0}=I_{k 3}+\frac{\left(1-M_{C 2}\right)}{\lambda+(1+n)^{2}} \cdot \frac{V_{i n} \cdot \Delta t_{4}}{L_{m}}, \\
I_{m 0}=I_{m 3}+\frac{\left(1-M_{C 2}\right)(1+n)}{\lambda+(1+n)^{2}} \cdot \frac{V_{i n} \cdot \Delta t_{4}}{L_{m}} .
\end{gathered}
$$

In short, Figure 3 presents the main theoretical waveforms in steady-state for all four operation stages. Through this graphic, the behavior of the system elements can be observed and, in conjunction with the stages presented in Figure 2, a mathematical model that represents the operation of the proposed converter can be obtained. It is important to observe in the second stage with $S$ turning-on, when condition $V_{L m}+V_{\text {Son }}>V_{\text {in }}$ is satisfied, the $L_{k}$ current slope can be negative.

\section{STATIC MODEL}

The mathematical model described by equations (2) to (9) defines the fundamental equations of the converter in steadystate. The system has 14 variables, so 14 equations linearly independent are required for solving it. Therefore, in addition to the equations related to the voltages across inductors $L_{m}$ and $L_{k}$ under each operation stage and the on and off times of $S$ as function of the duty cycle $D$ presented in equations (10) and (11), a Volt-second balance of inductors $L_{m}$ and $L_{k}$ and the Ampère-second balance of capacitors $C_{1}$ and $C_{2}$ are also needed, provided by equations (12) to (14). The model becomes complete with the sum of voltages across capacitors $C_{1}$ and $C_{2}$, which are equal to $V_{o}$.

$$
\begin{gathered}
\Delta t_{1}+\Delta t_{2}=D \cdot T_{s} \\
\Delta t_{3}+\Delta t_{4}=(1-D) \cdot T_{s} \\
-M_{C 2} \Delta t_{1}+M_{C 1}\left(\Delta t_{2}+\Delta t_{3}\right)+\left(\frac{\left(1-M_{C 2}\right)(n+1) n}{\lambda+(n+1)^{2}}\right) \Delta t_{4}=0 \\
\left(n+M_{C 2}\right) \Delta t_{1}+\left(n-M_{C 1}\right)\left(\Delta t_{2}+\Delta t_{3}\right)+ \\
n \Delta t_{2} \frac{I_{k 1}+I_{k 2}-I_{m 1}-I_{m 2}+n \Delta t_{3} \frac{I_{k 2}+I_{k 3}-I_{m 2}-I_{m 3}}{2}}{2} \\
-\Delta t_{4} \frac{I_{k 3}+I_{k 0}}{2}+n \Delta t_{1} \frac{\left(1-I_{C 2}+I_{k 1}-I_{m 0}-I_{m 1}\right.}{2}=0 \\
M_{C 1}+M_{C 2}=M
\end{gathered}
$$

As can be observed, the obtained equation set is not trivial to solve and does not allow algebraic solution, just numerical. Therefore, in this work a solution is presented assuming the voltages across capacitors $C_{1}$ and $C_{2}$ are previously known. In this way, by using equations (12) to
(14), the time intervals presented in equations (16) to (19) can be derived.

$$
\begin{gathered}
\Delta t_{1}=\frac{1+M D-M_{C 2}}{M} \cdot T_{s}, \\
\Delta t_{2}=\frac{M_{C 2}-1}{M} \cdot T_{s}, \\
\Delta t_{3}=\frac{M_{C 2}[D(n+\lambda+1)-\lambda]+D n(n+1)+\lambda n^{2}}{(M-1)(n+1)+M_{C 1}\left[n^{2}(\lambda+1)+n\right]} \cdot T_{s},
\end{gathered}
$$

and

$$
\Delta t_{4}=\frac{\left[\lambda+(n+1)^{2}\right][M(1-D)-1]}{(M-1)(n+1)+M_{C 1}\left[n^{2}(\lambda+1)+n\right]} \cdot T_{s} .
$$

Once knowing all time intervals $\Delta t_{i}$, the currents which refer to $L_{k}$ can be derived. So,

$$
\begin{gathered}
I_{k 0}=\frac{M_{C 2}(1+n \lambda)+n}{n^{2}} \cdot \frac{V_{i n} \cdot \Delta t_{1}}{\lambda L_{m}}, \\
I_{k 1}=\frac{M_{C 2}(n+\lambda+1)+n(n+1)}{n^{2}} \cdot \frac{V_{i n} \cdot \Delta t_{1}}{\lambda L_{m}}, \\
I_{k 2}=\frac{M_{C 2}(n+\lambda+1)+n(n+1)}{M_{C 1} n+n^{2}} \cdot \frac{\eta_{i n}^{2} \cdot \Delta t_{2}}{\lambda t_{1}}+ \\
-\frac{V^{2}}{\lambda L_{m}}
\end{gathered}
$$

and

$$
I_{d 3}=h_{2}+\left(1+\lambda n^{2} M_{C 2}\right) \Delta t_{1}+\Delta t_{2}+(1-M) \Delta t_{3} \cdot \frac{V_{i n}}{\lambda L_{m}},
$$

where

$$
h_{2}=\left\{\left[M_{C 2}(1+n)+n\right] \Delta t_{1}-M_{C 1} n\left(\Delta t_{2}+\Delta t_{3}\right)\right\} \cdot \frac{V_{i n}}{n^{2}} .
$$

For solving the whole system, the currents related to $L_{m}$ need to be obtained too. Therefore,

$$
\begin{gathered}
I_{m 2}=\frac{M_{C 2}(n+\lambda+1)+n(n+1)}{n^{2}} \cdot \frac{V_{i n} \cdot \Delta t_{1}}{\lambda L_{m}}+\frac{M_{C 1}}{n} \cdot \frac{V_{i n} \cdot \Delta t_{2}}{L_{m}} . \\
I_{m 3}=I_{k 3}(n+1) .
\end{gathered}
$$

After knowing all necessary quantities to define the system elements, we have:

$$
\begin{gathered}
L_{m}=\frac{M_{C 1}\left(\Delta t_{2}+\Delta t_{3}\right)}{n \cdot \Delta I_{L m}} \cdot V_{i n}, \\
C_{1}=\frac{\left(I_{k 2}+I_{k 3}-I_{m 2}-I_{m 3}+n I_{k 2}+n I_{k 3}-2 n I_{o}\right) \Delta t_{3}}{2 n \cdot \Delta V_{C 1}}
\end{gathered}
$$

and

$$
C_{2}=\frac{\left(I_{k 2}+I_{k 3}-2 I_{o}\right) \Delta t_{3}}{2 \Delta V_{C 2}},
$$

where $\Delta I_{L m}$ is the current ripple in $L_{m}$, and $\Delta V_{C 1}$ and $\Delta V_{C 2}$ the voltage ripples across $C_{1}$ and $C_{2}$.

It is known that the leakage inductance is influenced by many factors such as core material, turns ratio, winding number, winding technique, tightness between two windings, etc. [27]. That is, the leakage inductance is hard to design except for customization. Hence, in order to verify its influence in the proposed converter, in this work it is assumed that the maximum leakage inductance value is equal to $2 \%$ of $L_{m}$. Thus, $L_{k}$ can be computed through Equation 
(1). In practice, the coupled inductor is designed based on the magnetizing inductance, and afterwards the leakage inductance is obtained based on measurements.

\section{A. Static Gain}

As presented in the development of the static model, an analytic solution for the system variables could not be obtained. Therefore, the relation between output voltages $V_{C 1}, V_{C 2}$ and $V_{o}$, and the input voltage $V_{i n}$, which define the converter gains $M_{C 1}, M_{C 2}$ and $M$, respectively, are presented numerically as function of the duty cycle $D$ for distinct values of $n$, considering a specific value for $\lambda$. In the waveforms presented in Figure 4 , a $\lambda=2 \%$ is used. Analyzing Figure 4 , it is possible to define which operation point the converter must operate. As design procedure, the values for the voltages across capacitors $C_{1}$ and $C_{2}$ are defined, and the values for $n$ and $D$ can be obtained, or otherwise, obtain the desired voltage values from $n$ and $D$. In this work, the adopted criterion is to define the operation range where neither $D$ nor $n$ be high in order to achieve a high efficiency of the system
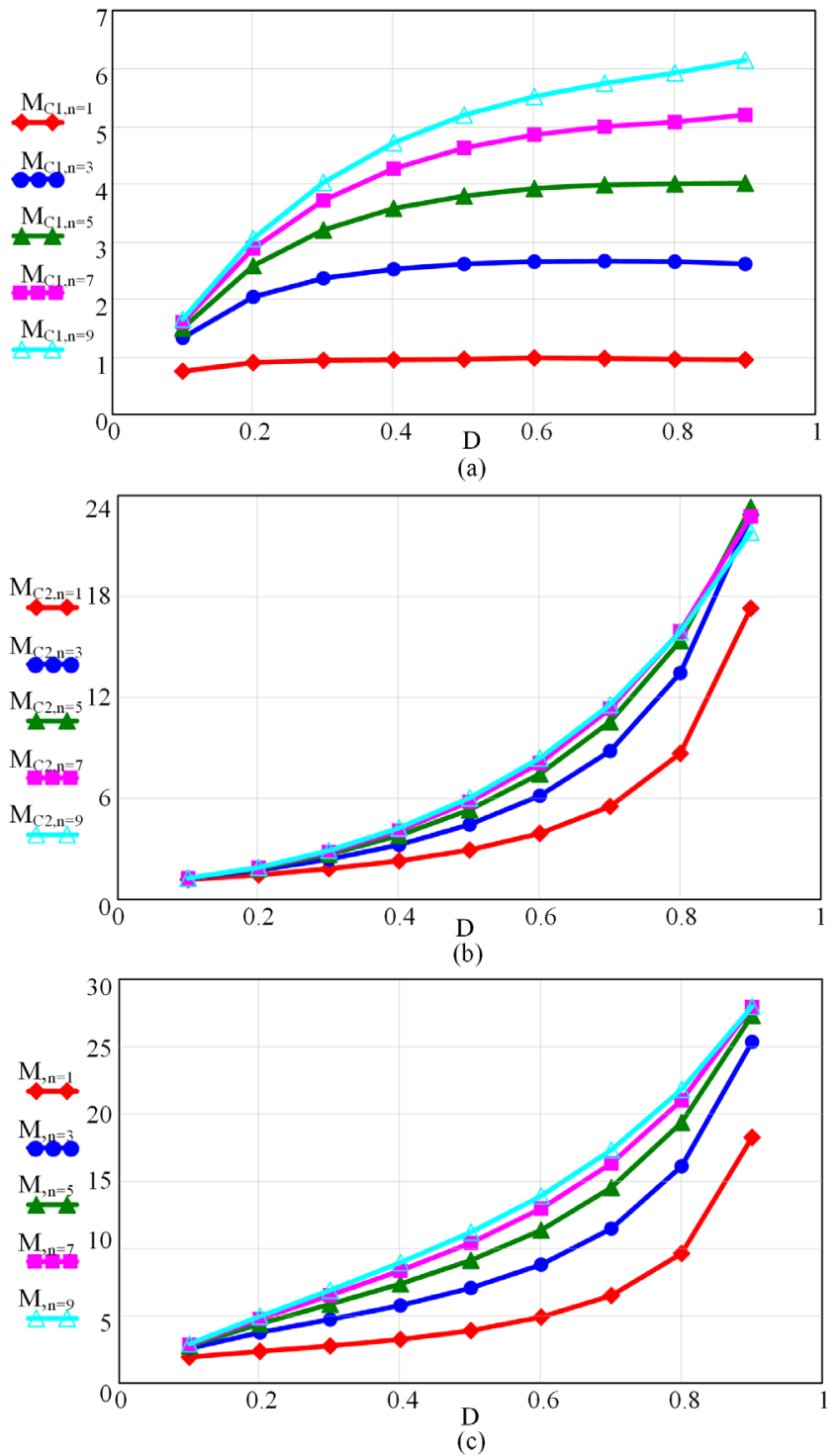

Fig. 4. Static gains of the converter as function of $D$ for different $n$ with $\lambda=2 \%$ : (a) $M_{C 1}$; (b) $M_{C 2}$; (c) $M$.

\section{B. Ideal converter}

As discussed previously, when considering the leakage inductance $L_{k}$, the static gain of the converter can only be derived from numeric solution. However, it can be demonstrated that the influence of $L_{k}$ does not affect significantly the total voltage gain $M$. Therefore, it is also important to present the ideal model of the converter and use it as a design reference for the non-ideal converter. By disregarding inductor $L_{k}$, equations for $M_{C 1}, M_{C 2}$ and $M$ can be defined, as stated in equations (30), (31) and (32). It can be noted that the total gain obtained in Equation (32) is greater than the one presented in [7].

$$
\begin{gathered}
M_{C 1}=n . \\
M_{C 2}=1+\frac{D(n+1)}{(1-D)} \\
M=\frac{n+1}{1-D} .
\end{gathered}
$$

Figure 5 shows the curves of gain $M$ as function of $D$, for $\lambda=0, \lambda=1 \%$ and $\lambda=2 \%$. It can be observed that with duty cycle $D$ neither too high nor too low $(0.2 \leq D \leq 0.8)$, the gain $M$ presents few differences between the ideal and non-ideal models. In such conditions, it can be stated that when the system operates in closed loop these differences can be easily compensated, without large control efforts.

For $\lambda=0$, equations for $L_{m}, C_{I}$ and $C_{2}$ can be derived too, as seen in Eqs. (33), (34) and (35).

$$
\begin{gathered}
L_{m}=\frac{V_{\text {in }} D}{\Delta I_{L m} f_{s}} \\
C_{1}=\frac{P_{o}(1-D)}{M V_{i n} \Delta V_{C 1} f_{s}} \\
C_{2}=\frac{P_{o} D}{M V_{i n} \Delta V_{C 2} f_{s}} .
\end{gathered}
$$

By disregarding $L k$, there are no voltage spikes and the blocking voltage levels across the semiconductors during a switching period are:

$$
\begin{gathered}
V_{D S}=\left(1+\frac{M_{C 2}}{n}\right) \cdot V_{i n} \\
V_{D 1}=(M-n+1) \cdot V_{i n} \\
V_{D 2}=M \cdot V_{i n} .
\end{gathered}
$$

To finish the theoretical analysis of the proposed

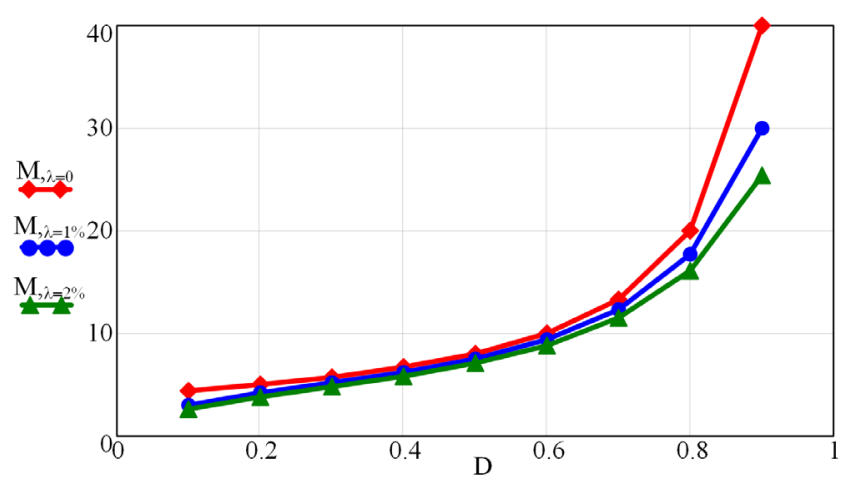

Fig. 5. Static gains of the ideal converter as function of $D$ for $\lambda=0$ $\%, 1 \%$ and $2 \%$ with $n=3$. 
Table I

Performance Comparation With Others Single Switch Converters

\begin{tabular}{|c|c|c|c|c|c|c|c|}
\hline \multirow{2}{*}{$\begin{array}{l}\text { Coupled-inductor Based } \\
\text { Circuit }\end{array}$} & \multirow{2}{*}{$\begin{array}{l}\text { Ideal Voltage Gain } \\
\qquad\left(V_{o} / V_{i n}\right)\end{array}$} & \multirow{2}{*}{$\begin{array}{l}\text { Voltage stress on the } \\
\text { main switch }\end{array}$} & \multicolumn{2}{|c|}{$\begin{array}{c}\text { No. of } \\
\text { Semiconductors }\end{array}$} & \multicolumn{2}{|c|}{$\begin{array}{l}\text { No. of Passive } \\
\text { Components }\end{array}$} & \multirow{2}{*}{$\begin{array}{l}\text { Clamp } \\
\text { circuit }\end{array}$} \\
\hline & & & Diode & Switch & Inductor & Capacitor & \\
\hline Proposed Converter & $\frac{1+n}{1-D}$ & $M \cdot V_{\text {in }}$ & 2 & 1 & 1 & 2 & No \\
\hline Converter in [4] & $\frac{1+n}{1-D}$ & - & 3 & 1 & 1 & 3 & No \\
\hline Converter in [9] & $\frac{1+n D}{1-D}$ & $\frac{n D}{1-D} \cdot V_{i n}$ & 2 & 1 & 1 & 2 & Yes \\
\hline Converter in [11] & $\frac{1+n D}{1-D}+n$ & $\frac{(M-n)}{1+n} \cdot V_{i n}$ & 4 & 1 & 1 & 4 & No \\
\hline Converter in [18] & $\frac{1+D}{1-D} \cdot n$ & $\frac{V_{i n}}{1-D}$ & 3 & 1 & 1 & 3 & Yes \\
\hline Converter in [19] & $\frac{1+D}{1-D} \cdot n$ & $\frac{V_{\text {in }}}{1-D}$ & 5 & 1 & 2 & 4 & No \\
\hline Converter in [21] & $\frac{D}{1-D} \cdot(1+n)$ & $\frac{V_{i n}}{1-D}$ & 2 & 1 & 1 & 2 & Yes \\
\hline
\end{tabular}

converter, a comparative performance with other converters based on the boost topology employing coupled inductor is presented in the Table I. The chosen initial criteria for comparison are the single switch and the pulsating input current performed by all circuits. The proposed circuit in [4] is based on in [9], however employing voltage multiplier and consequently naturally clamp on diodes, thus the components count is higher. The converters of [9] and [21] have the same components count than the proposed converter, but their voltage gains are lower and a clamp circuit to avoid voltages spikes on the semiconductors is necessary in both circuits. Regarding to the proposed circuits in [11], [18] and [19], all employ more components than the circuit in this work, however the voltage gains are higher.

\section{DYNAMIC MODEL}

Through the static model of the converter it is possible to define a design procedure and specify all the elements of the system. However, when external disturbances or a variation on the input voltage occur, to guarantee the output voltage at its nominal value, the converter must operate in closed loop. Therefore, the dynamic model must be developed too. In this work, the derived small-signal model does not consider operation stages 1 and 3, presented in Figure 2, because their time intervals are too small and does not affect significantly the system dynamics. The technique used to derive the smallsignal model of the proposed converter is the state-space averaging approach, presented by [32], then the transfer functions can be determined according to equations (39) and (40), which represent the relations $I_{L m}(s) / D(s)$ and $V_{o}(s) / I_{L m}(s)$, respectively. The numeric values in these equations agree with the design values presented in the experimental results. Figure 6 shows the behavior of the system (in red: theoretical results, according to equations (39) and (40); in blue: simulation results) when a disturbance occurs in $D$, as seen in Figure 6.a, or in $I_{m}$, as seen in Figure 6.b. It can be observed that the theoretical results are similar to the simulation results, thus validating the presented dynamic model.

$$
\begin{aligned}
& \frac{I_{L m}(s)}{D(s)}=\frac{3.20 \cdot 10^{-19} s^{2}+4.08 \cdot 10^{-5} s+0.04}{6.25 \cdot 10^{-11} s^{2}+1.86 \cdot 10^{-8} s+4.83 \cdot 10^{-4}} \\
& \frac{V_{o}(s)}{I_{L m}(s)}=\frac{5.59 \cdot 10^{-17} s^{2}+8.48 \cdot 10^{-5} s+9.34 \cdot 10^{-4}}{-3.2 \cdot 10^{-19} s^{2}+4.08 \cdot 10^{-5} s+0.035} .
\end{aligned}
$$

\section{DESIGN PROCEDURE}

The main condition considered in the design procedure adopted in this work is to avoid excessive losses both in conduction and in switching. For this, the converter must operate with the duty cycle $D$ neither too high nor too low, even when subjected to an input voltage variation. Therefore,

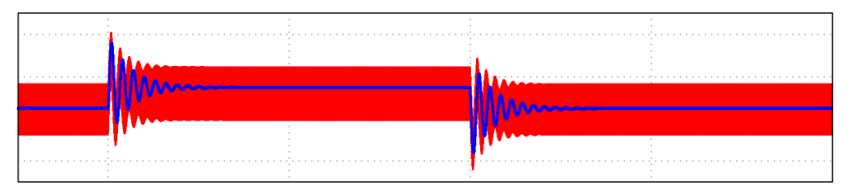

(a)

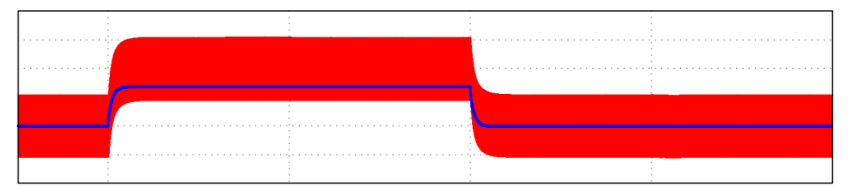

(b)

Fig. 6. Dynamic response of the system as function of external disturbances: (a) response of $I_{\text {in }}$ as function of a $4 \%$ variation in $D$; (b) response of $V_{o}$ as function of a $4 \%$ variation in $I_{i n}$. 
the undermentioned design steps 1 to 6 can be followed to define the parameters of the proposed converter assuming that the input source voltage varies between predefined minimum and maximum values. However, in the case the design considers the non-ideal converter, one must first assume a value for $\lambda$. The design procedure follows these steps:

1 - Define the ideal duty cycle $D$ operation range as a function of input voltage source variation $\Delta V_{i n}$;

2 - Obtain $n$ for the minimum input voltage by using (32);

3 - Calculate ideal $M_{C 1}$ and $M_{C 2}$ through (30) and (31), respectively;

4 - Assuming a $\lambda$ value, estimate $D_{\max }$ and $D_{\min }$ through Figure 5;

5 - Obtain the system variables presented in equations (16) and (26) by using ideal values for $M, M_{C 1}, M_{C 2}$ and $n$;

6 - Calculate non-ideal $L_{m}, C_{l}$ and $C_{2}$ using (27), (28) and (29), respectively, for the minimum and maximum values of $V_{\text {in }}$ and use the result that has the higher value.

When applying the design data presented in Table II, the converter parameters presented in Table III can be found. From Table III it is possible to specify the semiconductors and obtain the numerical values of the transfer functions to be used in the controller design, according to equations (39) and (40).

\section{EXPERIMENTAL RESULTS}

In order to verify the presented design methodology, experimental tests in open loop control were performed in a $300 \mathrm{~W}$ prototype of the proposed converter using data presented in TABLE II and III.

Figures 7.a and 7.b present the voltage waveforms on the

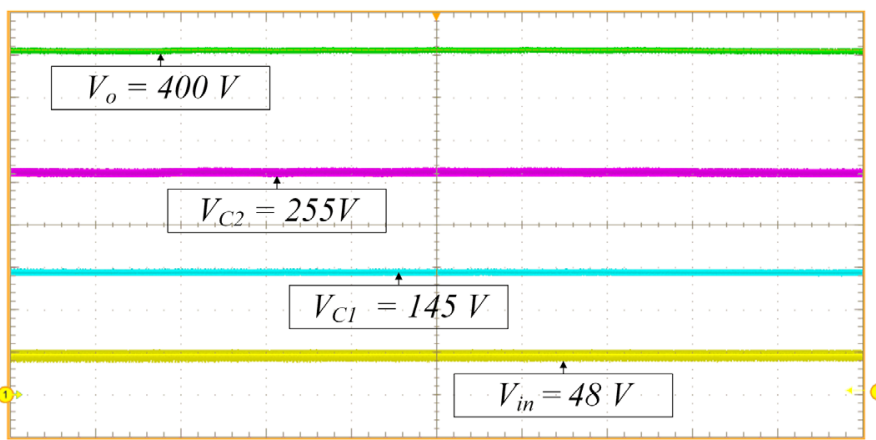

(a)
Table II

Design Specifications

\begin{tabular}{ccc}
\hline Parameter & Description & Value \\
\hline$V_{i n}$ & Input Voltage & $30 \mathrm{~V}-48 \mathrm{~V}$ \\
$f_{s}$ & Switching frequency & $100 \mathrm{kHz}$ \\
$P_{o}$ & Output power & $300 \mathrm{~W}$ \\
$V_{o}$ & Output Voltage & $400 \mathrm{~V}$ \\
$D$ & Real duty cycle & $0.720-0.56$ \\
$\lambda$ & Leakage factor & $1.8 \%$ \\
$M$ & Voltage gain & $13.33-8.33 \mathrm{~V}$ \\
$\Delta I_{L m}$ & Current ripple in $L_{m}$ & $20 \%$ of $I_{i n}$ \\
$\Delta V_{C l}$ & Voltage ripple in $C_{I}$ & $1 \%$ of $V_{C 1}$ \\
$\Delta V_{C 2}$ & Voltage ripple in $\mathrm{C}_{2}$ & $1 \%$ of $V_{C 2}$ \\
\hline
\end{tabular}

Table III

Calculated Parameters

\begin{tabular}{ccc}
\hline Parameter & Ideal Values & Non-ideal Values \\
\hline$n$ & 3 & 3 \\
$M_{C 1}$ & 3 & $2.63-2.76$ \\
$M_{C 2}$ & $10.33-5.33$ & $10.7-5.562$ \\
$V_{C 1}$ & $90 \mathrm{~V}-120 \mathrm{~V}$ & $89.35-143 \mathrm{~V}$ \\
$V_{C 2}$ & $310 \mathrm{~V}-280$ & $314-261.1 \sim \mathrm{V}$ \\
$I_{L m}$ & $10.57-6.25 \mathrm{~A}$ & $6.61 \sim 11.12 \mathrm{~A}$ \\
$L_{m}$ & $202 \mu \mathrm{H}$ & $200.2 \mu \mathrm{H}(\mathrm{E} 65 / 32 / 27)$ \\
$C_{1}$ & $2.55 \mu \mathrm{F}$ & $n_{p}=14 ; n_{s}=42$ \\
$C_{2}$ & $1.55 \mu \mathrm{F}$ & $3 \mu \mathrm{F}$ \\
$D_{1}-D_{2}$ & $\mathrm{C} 3 \mathrm{D} 10060 \mathrm{~A}$ & $2 \mu \mathrm{F}$ \\
$S$ & $\mathrm{SPW} 47 \mathrm{~N} 60 \mathrm{C} 3$ & $600 \mathrm{~V} / 10 \mathrm{~A}$ \\
\hline
\end{tabular}

$\mathrm{C}_{1}, C_{2}$ and on the load, for $V_{i n}=48 \mathrm{~V}$ (Figure 7.a) and $V_{i n}=$ $30 \mathrm{~V}$ (Figure 7.b). It can be observed that for a low value of $V_{i n}, V_{C 2}$ increases, because it is directly related to the duty cycle $D$. On the other hand, $V_{C l}$ decreases, because it depends only on $V_{\text {in }}$ and on the turns ratio $n$.

Figures 8.a and 8.b present the current waveforms in the coupled inductor primary-side winding and in $L m$, for $V_{i n}=48$

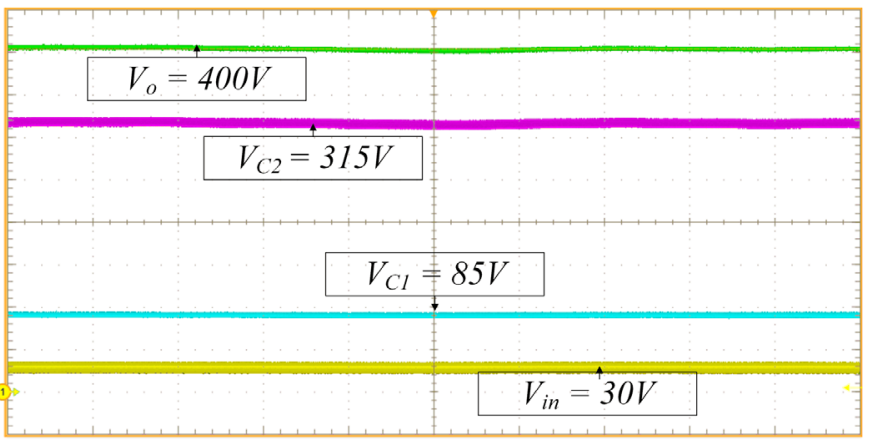

(b)

Fig. 7. Voltages on the capacitors $C_{l}$ and $C_{2}$ and on the load: (a) $V_{\text {in }}=48 \mathrm{~V}$; (b) $V_{\text {in }}=30 \mathrm{~V}$. (Scales: $\mathrm{v}=50 \mathrm{~V} / \mathrm{div} ; \mathrm{t}=10 \mathrm{~ms} / \mathrm{div}$ ).

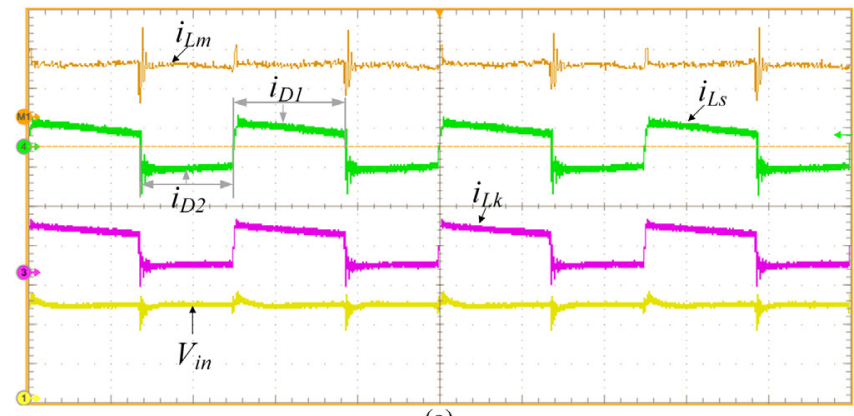

(a)

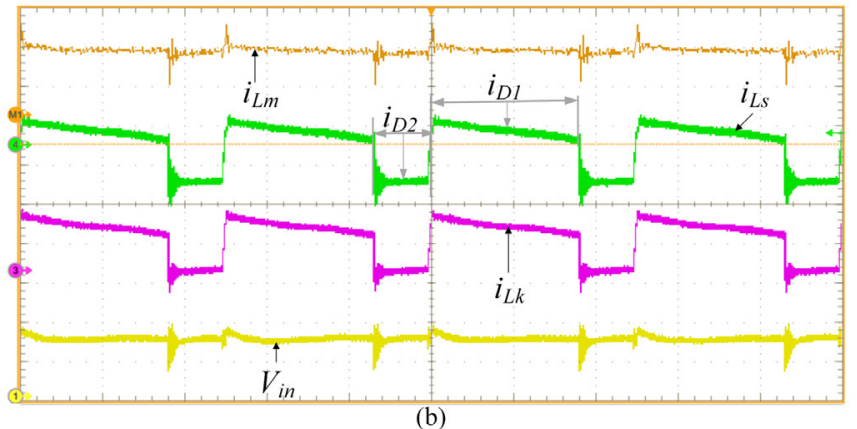

(b)

Fig. 8. Currents on inductors $L_{d}, L_{s}$ and $L_{m}$ : (a) $V_{i n}=48 \mathrm{~V}$; (b) $V_{i n}=30 \mathrm{~V}$. (Scales: $\mathrm{CH} 1=50 \mathrm{~V} / \mathrm{div} ; \mathrm{CH} 3=10 \mathrm{~A} / \mathrm{div} ; \mathrm{M} 1=5 \mathrm{~A} / \mathrm{div}$; $\mathrm{t}=$ $4 \mu \mathrm{s} / \mathrm{div})$. 


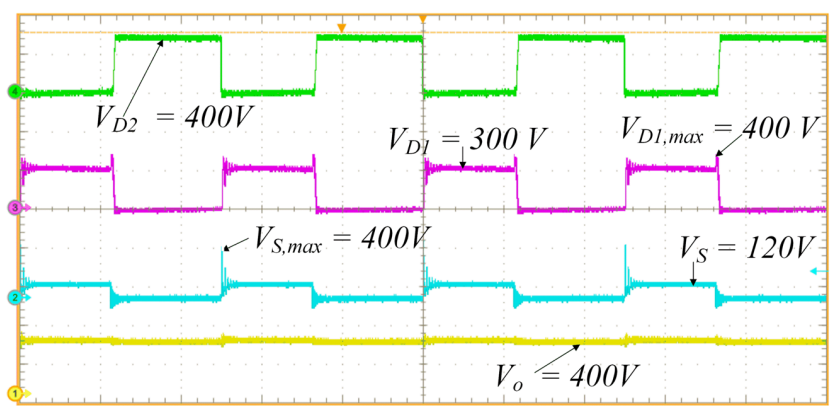

(a)

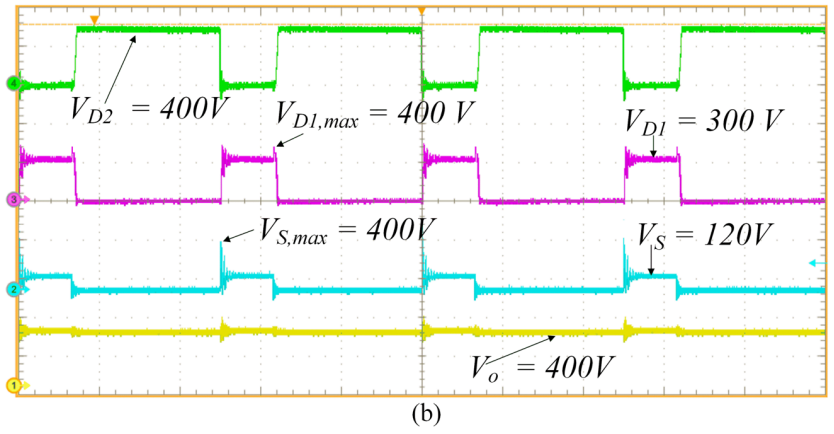

Fig. 9. Voltages across the switches used in the prototype: (a) $V_{\text {in }}$ $=48 \mathrm{~V}$; (b) $V_{\text {in }}=30 \mathrm{~V}$. (Scales: $\mathrm{v}=300 \mathrm{~V} /$ div; $\mathrm{t}=4 \mu \mathrm{s} /$ div).

$\mathrm{V}$ (Figure 8.a) and $V_{\text {in }}=30 \mathrm{~V}$ (Figure 8.b). In this measurement, the current $i_{L m}$ was acquired by using the scope's math resources, where $i_{L m}=i_{L k^{-}} i_{T s^{*}} n$. It can be seen that the converter operates with pulsating current in the input source. Therefore, in applications where a considerably high voltage gain is required, the efficiency may be impaired. Figures 9.a and 9.b show the waveforms of the voltages on the semiconductors $S, D_{1}$ and $D_{2}$ and on the load, for $V_{i n}=48$ $\mathrm{V}$ (Figure 9.a) and $V_{\text {in }}=30 \mathrm{~V}$ (Figure 9.b). It can be observed that none of the voltage spikes exceed the output value (400 V) and the blocking voltage values are close to those defined by (36), thus contributing to enhance the overall efficiency.

Figure 10 demonstrates the switching instants on $S$. Even though the ZVS not being achieved, as can be seen in the Figure 10.a, the switching losses are low because in the region which there are simultaneous voltage and current, both values are low and the transient time is too short. As can be observed in the Figure 10.b, the switching losses are more expressive during turn-off instant time and the voltage spike on the switch is around $400 \mathrm{~V}$.

Figure 11 presents the system efficiency measured with a Yokogawa W500 precision wattmeter. As can be noted, the efficiency of the converter operating with $V_{i n}=30 \mathrm{~V}$ is not so high when compared to the result obtained for $48 \mathrm{~V}$ that has presented a maximum efficiency of $95.2 \%$.

The efficiency curve under duty cycle $D$ variation is presented in the Figure 12 witch along with Figure 11 suggests that the proposed topology is more indicated for applications where extreme duty cycle values must be avoided to increase the system static gain. However, it may be necessary to carry out a more precise evaluation in the process of energy transference between input and output stages analysing the influence of the turns ratio $n$ where it should be considered that its increase implies in more leakage inductance and consequently in a lower static gain. Thus, to maintain the output voltage, the duty cycle should

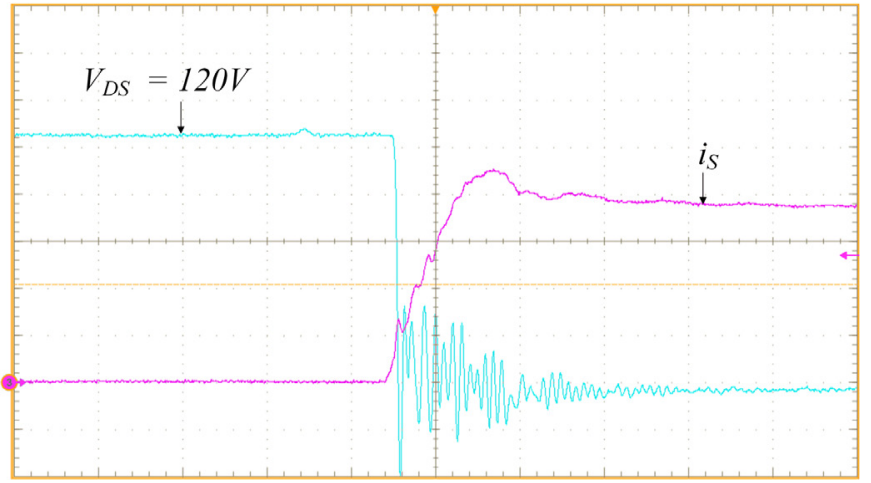

(a)

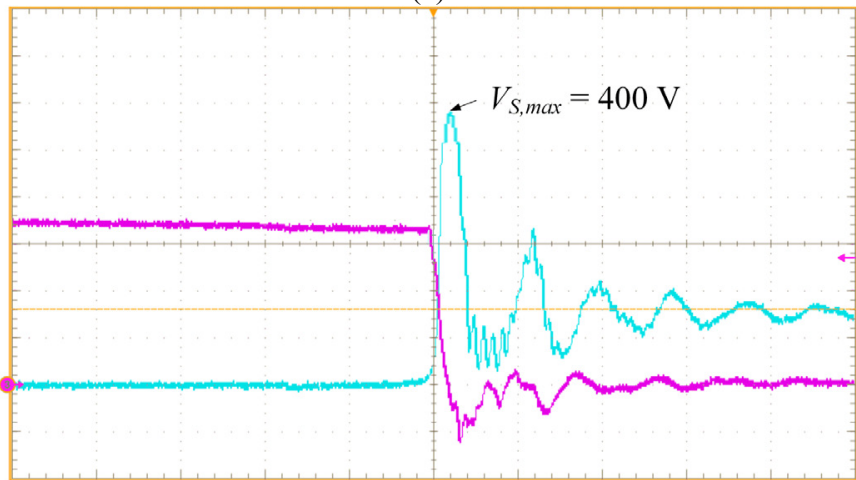

(b)

Fig. 10. Turn-on and turn-off transient instants of switch $S$. (Scales: (a): $\mathrm{v}=20 \mathrm{~V} / \mathrm{div} ; \mathrm{i}:=3 \mathrm{~A} / \operatorname{div} ; \mathrm{t}=160 \mathrm{~ns} / \mathrm{div}) ;(\mathrm{b}): \mathrm{v}=70 \mathrm{~V} / \mathrm{div}$; $\mathrm{i}:=3 \mathrm{~A} / \operatorname{div} ; \mathrm{t}=160 \mathrm{~ns} / \operatorname{div})$;

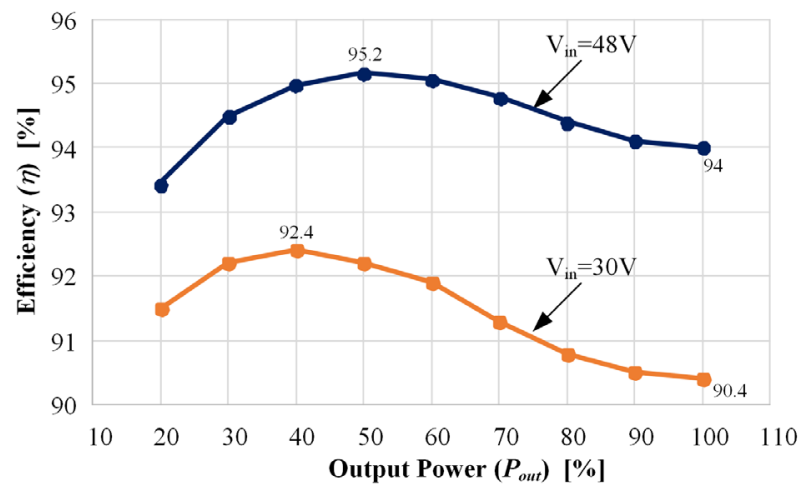

Fig. 11. Efficiency curves as function of the variation of the output power.

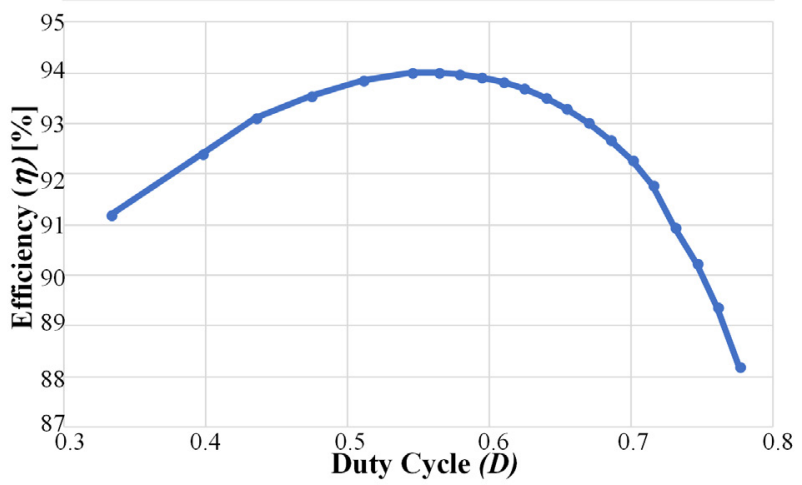

Fig. 12. Efficiency curve as function of the variation of the duty cycle $D$.

also be increased. On the other hand, no doubt that conduction losses are predominant for any input voltage 
level, indicating that the proposed circuit presented in Figure 1.b can be a good solution to improve the overall system efficiency, even for low and high duty cycle values.

\section{CONCLUSION}

This paper presents a high-voltage-gain dc-dc converter based on the boost converter employing coupled inductor. The main positive characteristics of the proposed topology is the elevated efficiency, natural voltage clamping in all semiconductors without using snubber circuits and reduced component count. The negative characteristics are the pulsating current on the input source which require a filter on applications that need reduced current ripple, and the maximum voltage spikes on semiconductors are equal to the output voltage.

From the operation stages and waveforms in steady state, considering the leakage inductance influence, a mathematical analysis was developed, thus the static and dynamic models of the converter were obtained. These models are required to specify all elements employed in the power circuit as well as to design control. The ideal converter model was also introduced and it can be observed that within a range operation of the duty cycle, there is no relevant influence of the leakage inductance, allowing the converter to be designed employing its ideal model. Thus, the design procedure can be considerably simplified without significant influence on the results.

Aiming to validate the proposed design methodology, experimental results in open loop control with a prototype of $300 \mathrm{~W}$ output power, $400 \mathrm{~V}$ output voltage and input voltage range of $30 \mathrm{~V}$ to $48 \mathrm{~V}$, with the converter operating at 100 $\mathrm{kHz}$ were presented. Examining the efficiency curves obtained from measurement on the prototype, one can see that the best converter performance occurs for a voltage around $48 \mathrm{~V}$, when maximum and nominal efficiencies of $95.2 \%$ and $94 \%$, respectively, were achieved.

The obtained results show that the voltage spikes on all semiconductors were clamped with its maximum value equal to the output voltage, demonstrating that no auxiliary clamping circuits are necessary. Furthermore, new technologies of semiconductors, such as CoolMOS ${ }^{\mathrm{TM}}$, can easily handle such voltage levels, like the observed ones.

\section{REFERENCES}

[1] U.S. Energy Information Administration, 'International Energy Outlook', September 2017.

[2] J.M. Carrasco, L.G Franquelo, et al, "Power-Electronic Systems for the Grid Integration of Renewable Energy Sources: A Survey", IEEE Trans. Ind Electron., vol. 53, no 4, pp. 1002-1016, Aug. 2006.

[3] W. Li, and X. He, "Review of Nonisolated High-StepUp DC/DC Converters in Photovoltaic Grid-Connected Applications," IEEE Trans. Ind. Electron., vol. 58, no. 4, pp. 1239-1250, Apr. 2011.

[4] G. Spiazzi, P. Mattavelli, J. R. Gazoli, R. Magalhaes and G. Frattini, "Improved Integrated Boost-Flyback High Step-Up Converter", IEEE International
Conference on Industrial Technology, Vina del Mar, 2010, pp. 1169-1174, 2010.

[5] H. Liu, H. Hu, H. Wu, Y. Xing and I. Batarseh, "Overview of High-Step-Up Coupled-Inductor Boost Converters", IEEE Journal of Emerg. and Selec. Top. in Power Electron., vol. 04, no. 2, pp. 689-704, Jun. 2016.

[6] M. Forouzesh, Y. P. Siwakoti, S. A. G. F. Blaabjerg, B. Lehman, "Step-Up DC-DC Converters: A Comprehensive Review of Voltage-Boosting Techniques, Topologies, and Applications", IEEE Trans. Power Electron, vol. 32, no. 12, pp. 9143-9178, Dec. 2017.

[7] J. R. Dreher, A. M. S. S. Andrade, L. Schuch and M. L. S. Martins, "Coupled-Inductor High Step-Up Integrated Topologies: Synthesis, Analysis and Experimental Results", Revista Eletrônica de Potência, v. 21, n.2, p. 091-104, mar./jun. 2016.

[8] A. M.S.S. Andrade, H. L. Hey, L. Schuch, M. L. S Martins, "Comparative Evaluation of Single Switch High Voltage Step-Up Topologies Based on Boost and Zeta PWM Cells", IEEE Trans. Ind. Electron., vol. 65, no. 3, pp. 2322-2334, 2018.

[9] K. C. Tseng and T. J. Liang "Novel high-efficiency step-up converter", IEE Proc. - Electric Power App., vol. 151, no 2, pp.: 182-190, Mar. 2004.

[10] H. Ardi, A. Ajami and M. Sabahi, "A Novel High Stepup DC-DC converter with Continuous Input Current Integrating Coupled Inductor for Renewable Energy Applications", IEEE Trans. Ind. Electron., vol. 65, no. 2, pp. 1306-1315, Feb. 2018.

[11] Y. P Hsieh, T.J Liang, L.S. Yang, “A Novel High StepUp DC-DC Converter for a Microgrid System", IEEE Trans. Power Electron., vol. 26, no 4, pp. 1129-1136, Apr. 2011.

[12] P. Saadat, K. Abbaszadeh, "A Single-Switch High StepUp DC-DC Converter Based on Quadratic Boost", IEEE Trans. Ind. Electron., vol. 63, no 12, pp. 77337742, Dec. 2016.

[13] M. Forouzesh, Y. Shen, K. Yari, Y.P. Siwakoti, F. Blaabjerg, "High-Efficiency High Step-Up DC-DC Converter With Dual Coupled Inductors for GridConnected Photovoltaic Systems", IEEE Trans. Power Electron., vol. 33, no7, pp. 5967-5982, Jul. 2018.

[14] E. Babaei, Z. Saadatizadeh, "High voltage gain dc-dc converters based on coupled inductors", IET Power Electron., vol. 11, no 3, pp. 434-452, Mar. 2018.

[15] L. Schmitz, D.C. Martins, R. F. Coelho, "Generalized High Step-Up DC-DC Boost-Based Converter With Gain Cell", IEEE Trans. Circ. and Systems - I: Regular Papers, vol. 64, no. 2, pp. 480-493, 2017.

[16] S. Sathyan, H. M. Suryawanshi, M. Sudhakar Ballal, and A. B. Shitole, " Soft-Switching DC-DC Converter for Distributed Energy Sources With High Step-Up Voltage Capability", IEEE Trans. Ind. Electron., vol. 62, no. 11, pp. 7039-7050, 2015.

[17] R. G. A. Cacau, T. B. Lazzarin1, M. C. T. Villanueva, I. Barbi "Study of High Step-up Gain DC-DD Converters Based on Stacking ff Non-Isolated Topologies" Revista Eletrônica de Potência, v. 23, n.4, p. 505-515, out./dez. 2018. 
[18] J.W. Baek, M.H., T.J. Ryoo, Kim, D.W. Yoo, J.S. Kim, "High Boost Converter Using Voltage multiplier," IEEE IECON, Nov. 2005.

[19] Y. Zhao, W. Li, X. He, "High step-up boost converter with passive lossless clamp circuit for non-isolated high step-up applications", IET Power Electron., vol. 4, no. 8, pp. 851-859, Jan. 2011.

[20] J.H. Lee, T.J. Liang, J. F. Chen, "Isolated CoupledInductor-Integrated DC-DC Converter with Non dissipative Snubber for Solar Energy Applications", IEEE Trans. on Ind. Electron., vol. 61, no. 7, pp. $3337-$ 3348, Aug. 2014.

[21] D. Yu, J. Yang, R. Xu, et al. "A Family of ModuleIntegrated High Step-up Converters with Dual Coupled Inductors" IEEE Early Access Articles, no. 6, pp. 16256-16265, Mar. 2018.

[22] Q. Zhao, F.C. Lee, "High-Efficiency, High Step-Up DC-DC Converters", IEEE Trans. Power Electron., vol. 18, no. 1, pp. 65-73, Mar. 2003.

[23] A. M. S. S. Andrade, E. Mattos, L. Schuch, H. L. Hey and M. L. S. Martins, "Synthesis and Comparative Analysis of Very High Step-Up DC-DC Converters Adopting Coupled-Inductor and Voltage Multiplier Cells", IEEE Trans. Power Electron, vol. 33, no. 7, pp. 5880-5897, Aug. 2018.

[24] C. Tseng, C. A. Cheng and C. T. Chen, "High Step-Up Interleaved Boost Converter for Distributed Generation Using Renewable and Alternative Power Sources", IEEE Journal of Emerg. and Selec. Top. in Power Electron, vol. 5, no. 2, pp. 713-722, Jun. 2017.

[25] H. Ardi, A. Ajami and M. Sabahi, "A Novel High Stepup DC-DC converter with Continuous Input Current Integrating Coupled Inductor for Renewable Energy Applications", IEEE Trans. Ind. Electron., vol. 65, no. 2, pp. 1306-1315, Feb. 2018.

[26] K.B., Park, G.W. Moon, M.J. Youn, "Nonisolated High Step-up Boost Converter Integrated With Sepic Converter", IEEE Trans. Power Electron., vol. 25, no. 9, pp. 2266-2275, 2010.

[27] S. W. Lee and H. L. Do, "Isolated SEPIC DC-DC Converter with Ripple-Free Input Current and Lossless
Snubber", IEEE Trans. Ind. Electron., vol. 65, no. 2, pp. 1254-1262, Feb. 2018.

[28] R. Moradpour, H. Ardi and A. Tavakoli, "Design and Implementation of a New SEPIC-Based High Step-Up DC/DC Converter for Renewable Energy Applications", IEEE Trans. Ind. Electron, vol. 65, no. 2, pp. 1290-1297, Feb. 2018.

[29] S. W. Lee and H. L. Do, "Zero-Ripple Input-Current High-Step-Up Boost-SEPIC DC-DC Converter With Reduced Switch-Voltage Stress", IEEE Trans. Power Electron., vol. 32, no. 8, pp. 6170-6177, Aug. 2017.

[30] E. Gurpinar, A. Castellazzi, "Single-Phase T-Type Inverter Performance Benchmark Using Si IGBTs, SiC MOSFETs, and GaN HEMTs", IEEE Trans. Power Electron., vol. 31, no. 10, pp. 7148-7160, Dec. 2016.

[31] P. Wong, P. Xu, P. Yang, F. C. Lee, "Performance improvements of interleaving VRMs with coupling inductors", IEEE Trans. Power Electron., vol. 16, no. 4, pp. 499-507, Jul. 2001.

[32] R. W. ERICKSON, D MAKSIMOVIĆ, "Fundamentals of power electronics", 2. ed., 6. printing ed. Norwell, Mass.: Kluwer Acad. Publ, 2004.

\section{BIOGRAPHIES}

Eduardo Silva Hass, born in 10/27/1992 in Ponta Gossa-PR is an electronic engineer (2015) and master (2017) with the Federal University of Technology - Parana.

His areas of interest are: power converters, digital controllers and renewable energy processing.

Claudinor Bitencourt Nascimento, born in 06/05/1971 in Tubarão-SC is an electrical engineer (1994), master (1996) and doctor (2005) in Electrical Engineering with the Federal University of Santa Catarina.

He is currently a titular professor at the Federal University of Technology - Parana. His areas of interest are: lighting system, power factor correction circuits and new converter topologies. 